\title{
Itinerários terapêuticos realizados por gestantes adeptas de religiões afro-brasileiras
}

\author{
Therapeutic itineraries performed by pregnant \\ women from afro-brazilian religions
}

\author{
Ricardo José Oliveira Mouta' 1 \\ Elizabeth Sabino dos Anjos ${ }^{2}$ \\ Juliana Amaral Prata 3 (i)
}

\author{
Aldira Samantha Garrido Teixeira 4 \\ Renata Pascoal Freire 5 \\ Fernanda Maria do Vale Martins Lopes $^{6}$
}

1Autor para correspondência. Universidade do Estado do Rio de Janeiro (Rio de Janeiro). Rio de Janeiro, Brasil. ricardomouta@hotmail.com 2,3,5,6Universidade do Estado do Rio de Janeiro (Rio de Janeiro). Rio de Janeiro, Brasil. elizabethsabinoborges@gmail.com, juaprata@gmail.com renatapfreire@gmail.com, fernandalopescfmso@gmail.com ${ }^{4}$ Universidade Federal Fluminense (Rio de Janeiro). Rio de Janeiro, Brasil. asamantha@id.uff.br

RESUMO | OBJETIVO: Conhecer os itinerários terapêuticos realizados por gestantes adeptas de religiões afro-brasileiras no Rio de Janeiro. METODOLOGIA: Estudo exploratório, descritivo e qualitativo, com 20 puérperas. Os dados foram coletados no período de julho a setembro de 2018, por meio de entrevistas, e submetidos à análise de conteúdo. RESULTADOS: As influências das religiões afro-brasileiras durante o período gravídico revelaram ações de cuidado que perpassam por acolher, apoiar, revigorar, tranquilizar-se e aceitar. Sobre os itinerários terapêuticos das participantes, constatou-se: consultares oraculares; rituais envolvendo orixás e guias espirituais; e práticas específicas para o parto. Ainda, as gestantes adeptas das religiões afro-brasileiras relataram situações de intolerância religiosa vivenciadas no ambiente familiar e no espaço do cuidado. CONCLUSÃO: As gestantes de religião afro-brasileira construíram itinerários terapêuticos no qual também mantinham vinculo com o serviço de prénatal, assim como eram acolhidas nos terreiros. As práticas religiosas atuaram como alternativa e/ ou complementariedade terapêutica no processo assistencial da gestação.

DESCRITORES: Gravidez. Diversidade Cultural. Religiões AfroBrasileiras. Itinerários Terapêuticos.

\begin{abstract}
OBJECTIVE: To know the therapeutic itineraries carried out by pregnant women who adhere to Afro-Brazilian religions in Rio de Janeiro. METHODOLOGY: Exploratory, descriptive, and qualitative study, with 20 postpartum women. Data were collected from July to September 2018 through interviews and submitted to content analysis. RESULTS: The influences of Afro-Brazilian religions during the pregnancy period revealed care actions that permeate by welcoming, supporting, reinvigorating, calming, and accepting. About the therapeutic itineraries of the participants, it was found: oracular consultations; rituals involving orixás and spiritual guides; and specific practices for childbirth. Also, pregnant women who adhere to Afro-Brazilian religions reported situations of religious intolerance experienced in the family environment and the space of care. CONCLUSION: AfroBrazilian pregnant women built therapeutic itineraries in which they also maintained a link with the prenatal service and were welcomed in the terreiros. Religious practices acted as an alternative and/or therapeutic complementarity in the care process of pregnancy.
\end{abstract}

DESCRIPTORS: Pregnancy. Cultural diversity. Afro-Brazilian Religions. Therapeutic Itineraries. 


\section{Introdução}

Religiões afro-brasileiras possuem sua essência teológica e filosófica oriundas das religiões tradicionais africanas. Os negros sequestrados na África e escravizados no Brasil descobriram que única forma de resguardar suas tradições, idiomas, conhecimentos e valores trazidos da África seria através da prática religiosa. ${ }^{1}$

Essas religiões são um espaço de construção de conhecimento, tendo suas práticas religiosas relação com a natureza e seres sagrados (orixás, divindades e entidades). O saber dessas religiões não se restringe a pensamentos, estendendo-se a práticas humanas mantidas com a vivência diária no núcleo religioso, permitindo constante aprendizagem. Os conhecimentos são transmitidos através da oralidade, socializando os adeptos ao terreiro, representando uma escola, estabelecendo assim laços de irmandade e solidariedade. As práticas, rituais e relações construídas possibilitam trocas afetivas, produção de conhecimentos, promoção da saúde e prevenção de doenças e agravos, além da valorização de tradições milenares, como o uso das plantas medicinais. $\frac{2,3}{3}$

Olódùmaré, nome do Deus supremo do povo yorubá, criou o mundo e as divindades - Orixás - intermediando a relação entre Deus e os homens. Orixás femininos, as Àyabás, são responsáveis pela fecundidade, pela riqueza e pela feminilidade. Senhora da beleza, das águas fluviais, do amor e do poder feminino, Oxum, que reina sobre a água doce dos rios, é também responsável pela fecundidade de todos os seres. ${ }^{4}$

Para cultura yorubá, sem o consentimento de Oxum, não há gravidez, pois ela é dona do líquido amniótico, e que toma conta das crianças desde a gestação até que elas aprendam a falar. Nessa cultura, as gestantes são tratadas de forma especial, pois são vistas como "ilóyún émí alafé" (grávidas de espíritos divinos), ou seja, quando um émí (espírito) é enviado para a terra, nasce com ele uma mãe, e esta mãe merece culto, já que sem seu ventre, não seria possível a vida. Nesse sentido, para as religiões afro-brasileiras, ser mãe é algo tão mágico que acaba contagiando a todos que estão ao seu redor.., 5

Já no campo da saúde, as gestantes adeptas de religiões afro-brasileiras trazem para as consultas de pré-natal práticas religiosas importantes, pouco conhecidas e, por vezes, rotuladas de forma preconceituosa por profissionais de saúde que desenvolvem a assistência baseada na racionalidade biomédica, desconsiderando saberes e práticas populares e de outras áreas do conhecimento.

Reconhecendo essa importância, o Sistema Único de Saúde (SUS) ampliou nas últimas décadas a atuação dos movimentos populares, desenvolvendo políticas públicas específicas para indígenas, negros, quilombolas, populações ribeirinhas, ciganas e em situação de rua. Dentre elas, destaque para a Política Nacional de Saúde Integral da População Negra no ano de 2009, que objetiva promover a saúde integral da população negra, reconhecendo e atuando nas desigualdades raciais e preconceitos existentes nas instituições de saúde. $\underline{6}$

Porém, ainda hoje, muitas mulheres, por dificuldades de acesso as redes de atenção a saúde, buscam outros tipos de cuidados, mobilizando diferentes recursos, tais como, cuidados caseiros, práticas religiosas na preservação ou recuperação da saúde, que são denominados itinerários terapêuticos. ${ }^{?}$

Esses itinerários são constituídos por todo tipo de movimento iniciado por indivíduos ou grupos na preservação ou recuperação da sua saúde. Considerase, nesse estudo, a concepção de itinerário terapêutico como um processo social, a partir dos significados culturalmente construídos. Eles atuam como instrumento que registra os processos de cuidado, principalmente nas limitações de acesso dessa população aos serviços formais de saúde, a busca pela autonomia, valorização das suas práticas de cuidado, além de ações de prevenção.

Importante destacar que como as práticas religiosas desempenhadas nesses espaços são fortemente transmitidas oralmente, ainda são escassos os registros a respeito da influência das religiões afro-brasileiras no período gestacional. Sendo assim, esse estudo visa contribuir nessa lacuna do conhecimento, visando melhorar o resultado na assistência obstétrica, bem como a satisfação, respeito e beneficio às mulheres adeptas dessas religiões.

Esse artigo tem como objetivo conhecer os itinerários terapêuticos realizados por gestantes adeptas de religiões afro-brasileiras no Rio de Janeiro. 


\section{Metodologia}

Estudo exploratório e descritivo, com abordagem qualitativa, tendo como participantes 20 puérperas adeptas das religiões afro-brasileiras. Como critérios de inclusão, adotou-se: mulheres que vivenciaram o momento gravídico enquanto adeptas das religiões afro-brasileiras. Foram excluídas as mulheres menores de 18 anos de idade.

Para a captação das participantes, utilizou-se a técnica da bola de ou cadeia de informantes, ou snowball. Neste sentido, a identificação das participantes da pesquisa e o recrutamento destas aconteceram conforme a amostragem por cadeia de informante, constituindo uma espécie de rede. Assim, 02 participantes foram consideradas como sementes, selecionadas intencionalmente pela facilidade de contato com um dos autores, as quais apontaram novas participantes potenciais, reconhecidas por seus pares em decorrência de sua atuação no terreiro, e assim sucessivamente, até o momento em que houve a repetição de conteúdos nas falas e estas não acrescentavam novas informações relevantes para o estudo, indicando a saturação dos dados.

Os dados foram coletados no período de julho a setembro de 2018, por meio de entrevistas individuais, baseadas em um roteiro semiestruturado. As entrevistas aconteceram por escolha das participantes no domicílio ou nos terreiros de religiões afro-brasileiras localizados no município do Rio de Janeiro, tiveram a duração média de 20 minutos, foram gravadas em MP3 (media player) e, posteriormente, transcritas na íntegra. Ressalta-se que foi realizada uma entrevista piloto, a qual indicou a adequabilidade do instrumento e que, por isso, foi incluída no corpus de análise. Ainda, acrescenta-se que não houve perdas ou recusas durante o processo de captação dos dados.

A análise de conteúdo foi escolhida por compreender criticamente o sentido das comunicações e suas significações explícitas ou ocultas. ${ }^{-}$Esse processo analítico conflui para a constituição de três categorias: "As influências das religiões afro-brasileiras durante o período gravídico"; "Os itinerários terapêuticos das gestantes adeptas as religiões afro-brasileiras"; e "Intolerâncias religiosas vivenciadas pelas gestantes adeptas das religiões afro-brasileiras".
O estudo foi submetido ao Comitê de Ética em Pesquisa da Universidade do Estado do Rio de Janeiro (CAAE: 93032918.2.0000.5282) e aprovado sob o parecer $n^{\circ} 2.776 .909$. Em atendimento aos aspectos éticos e legais de pesquisas com seres humanos, as participantes assinaram um Termo de Consentimento Livre e Esclarecido e tiveram seu anonimato garantido por meio do uso da letra " $E$ ", referente ao termo entrevistada, seguida de um número, que representa a ordem de realização da entrevista.

\section{Resultados e discussão}

As participantes deste estudo, em sua maioria, são umbandistas, com um tempo de religião de 15 a 21 anos, sua faixa etária se encontra entre 35 e 50 anos, são brancas e casadas, possuem nível médio de escolaridade, vinculo empregatício e apresentaram gestação classificadas como alto risco.

\section{As Influências das religiões afro-brasileiras durante o período gravídico}

Nos terreiros há espaço para cuidar e ser cuidado, ouvir e ser ouvido de modo que a religião altera a interpretação da doença e confere novos significados à vida diante do sofrimento. Neste sentido, se configura como uma rede de apoio que contribui para mudanças no estilo de vida, proporciona a sensação de acolhimento e bem-estar, bem como influencia positivamente na aceitação da comunidade à pessoa em processo de adoecimento. ${ }^{4}$

Igrejas, terreiros, centros espíritas, residências de pajés e curadores são diariamente procurados por pessoas doentes ou em sofrimento, na crença de que o sagrado age na prevenção e na cura. Para este grupo, a doença é vista como uma situação advinda de questões materiais, espirituais (espíritos, encantados, santos, castigos, provações, falta de proteção e encosto) e mágicos (malefícios causados por magia, bruxaria e feitiço).

Assim, frente ao diagnóstico de gestação de alto risco, evidenciou-se que a maioria das gestantes adeptas das religiões afro-brasileiras recorre às práticas no terreiro, onde encontram ações de cuidado que perpassam por: acolher, apoiar, revigorar, tranquilizar-se e aceitar. 
Acolher é um compromisso de resposta às necessidades dos cidadãos que procuram os serviços de saúde, pressupondo postura ética que implica na escuta do usuário em suas queixas, no reconhecimento do seu protagonismo no processo de saúde e adoecimento, na responsabilização pela resolução, com ativação de redes de compartilhamento de saberes. ${ }^{9}$ Nas religiões afro-brasileiras, acolher é uma ação primordial, sendo o terreiro um espaço de escuta e ações para o reestabelecimento da saúde.

"Eu tive uma gestação que não era para ter acontecido e aconteceu graças aos trabalhos e a minha crença. Dentro da minha religião eu fui bem acolhida, bem tratada" (E01).

“... Desde o início (gravidez) busquei orientações em como cuidar da minha espiritualidade para passar por todo esse processo" (EO9).

As mulheres adeptas de religiões afro-brasileiras no período gestacional nem sempre encontram respostas para suas inquietações no serviço de saúde, buscando nas práticas religiosas uma forma de equilíbrio, que se reverte em suporte e segurança necessários à ressignificação do medo paralisante, tornando-as protagonistas do seu cuidado.

As práticas de saúde nos terreiros são baseadas em conhecimentos de longa tradição repassados de geração a geração através da oralidade. Neste processo, gestam-se concepções e práticas diversas que manifestam o caráter multicultural das religiões afrobrasileiras. 10

"A ajuda dos guias sempre é fundamental em nossas vidas e principalmente nas minhas gravidezes. Eu era muito nova e a orientação deles foi muito importante pra mim"(E11).

A religião é capaz de dar um sentido à doença, à cura e à saúde, fortalecendo a relação com a medicina. ${ }^{11}$ Mesmo reconhecendo a complementaridade das práticas espirituais e biológicas, alguns indivíduos conferem à religião maior importância, buscando um referencial mágico-religioso como explicação para seus males.
O período gestacional gerou nas gestantes entrevistadas diferentes sentimentos e emoções e inseguranças quanto ao futuro. Sentir-se apoiada no processo gestacional foi fundamental para lidar com as incertezas, e preocupações, tendo nas práticas religiosas um espaço de escuta e nos Orixás uma força para lidar com esse período.

"Tive momentos delicados e a religião me ensinou a acreditar na minha fé e em todos os meus Orixás. Vi que não estava sozinha, principalmente na hora do meu parto. Senti a presença dos meus orixás na sala de parto..."(E09).

Diferentes rituais, rezas e cantos foram entoados durante nas cerimônias de tratamento, invocando Orixás que atuam diretamente na saúde. Comidas sagradas foram preparadas como oferendas ou agrados, assim como as orientações e prescrições recebidas nos cultos religiosos foram realizadas pelos pacientes num sentido sacrificial.

“... A espiritualidade teve ação continua para segurar, para fazer com que o feto passasse dos três primeiros meses, para que eu não corresse nenhum risco de abortar" (E12).

As práticas realizadas contribuíram para o aumento da autoconfiança, potencializando o tratamento biomédico. A percepção de saúde, como um equilíbrio entre corpo e espírito, modela os caminhos de uma parcela desta população na busca de atendimento, do médico ao pai do santo, dos banhos de ervas para scanners computadorizados e tratamentos alopáticos. 12

\section{- Revigorar}

A gestação altera as condições psíquicas, emocionais e sociais, sendo fundamental um espaço para acoIher, revigorar e fortalecer.? Segundo as entrevistadas, o terreiro foi um espaço propício para revigorar, proporcionando maior tranquilidade e energia. A religião atuou de forma terapêutica, trazendo conforto e alívio. 12

“... fortaleceu minha energia e trabalhei até o final da gestação" (E02). 


\section{- Tranquilizar}

A consulta realizada no terreiro promove um diálogo franco e sensível no encontro da gestante com os Orixás. ${ }^{2}$ Durante as consultas vivenciadas pelas gestantes, foram prescritos cuidados de acordo com a necessidade, considerando a singularidade da muIher e sua família, atores principais do período gestacional.

"Eu ia às sessões principalmente de preto velho, caboclos e Ibejadas, pedindo passe e que eles olhassem por minhas gestações (...) Pedia para que corresse tudo bem durante o parto e na gestação. Graças a Deus e a

Eles também correu tudo na perfeita ordem" (E10).

Muitas gestantes relataram alívio para suas doenças após as sessões de Umbanda.

"Durante a gestação fiquei fazendo uso de medicação para pressão alta e fazendo todo trabalho no terreiro

de acalmar... Eu participava, pedia auxílio de um ou outro Orixá que vinha. Mandavam-me ficar tranquila e dizia ser tudo bem e foi" (E18).

\section{- Aceitar}

As mulheres adeptas das religiões afro-brasileiras encontraram na religião suporte para lidar com este momento singular que é a perda gestacional. Uma gestante espera a vida e não a morte, o ganho e não a perda.

A perda de um bebê por aborto, morte fetal ou neonatal é um acontecimento traumático, de intenso sofrimento, marcado por lembranças, pensamentos, fantasias e questionamentos de toda a experiência vivenciada. O retorno para casa e as ações cotidianas são tomadas de muita tristeza para essas mulheres. $O$ processo educativo da mediunidade traz em si ritos que podem exercer um poder benéfico e terapêutico. 13,14

"Ajudaram-me muito a entender quando perdi o segundo filho... É muito difícil a mãe entender que tinha que perder um filho ao sexto mês de gravidez... Esquecer a gente não vai, mas fizeram entender que eu tinha que passar por isso e que ele também, tanto para ajudar ele espiritualmente, como a mim também" (EO6).
A religião altera o significado da doença, modificando também sua visão do mundo para aqueles acometidos. ${ }^{3}$ A religião afro-descendente contribuiu na ressignificação da doença, atuando como um mecanismo de autoajuda.

"Quando eu tive o aborto do segundo filho, o centro me ajudou muito a entender que nada é por acaso e que as coisas acontecem de acordo com os propósitos de Deus. Então fui acalentada, porque quando a gente perde um bebê parece que tira um pedaço da gente...

Sofri muito, chorei pra caramba... Eles me fizeram enxergar que por mais que eu estivesse sofrendo eram

para as coisas terem acontecido desta forma e isso acalenta, acalma o coração" (E17).

\section{- A gestação inesperada}

Quando a gestação é inesperada, pode ser considerada para algumas mulheres como um acontecimento que pode atrapalhar planos, sonhos, tornando em alguns casos, uma gravidez indesejada. Nesses casos, os danos psíquico-afetivos podem ser grandes, pois o bebê percebe as emoções maternas, carregando estes sentimentos, sem entender o porquê. Além do vínculo mãe/bebê, a amamentação poderá ser prejudicada por conta destes sentimentos. ${ }^{2}$

As mulheres adeptas de religião afro-brasileiras encontraram na religião apoio e aceitação para esse momento, vendo como uma oportunidade para reavaliar suas relações afetivas.

"Tive uma gestação que não foi planejada... Então a religião, me deixou mais em paz, mais tranquila ao ser

informada que era naquele momento que tinha que acontecer e que meu filho tinha que vir para de repente

alguma coisa mudar. E foi isso que aconteceu, veio para melhorar a nossa vida e foi a minha religião que me deu essa força essa certeza" (E15).

"Fisiologicamente falando não teria como engravidar novamente, (...). Em contrapartida, me orientaram o quanto era necessário a vinda deste bebê... da missão espiritual que ela tem e da questão cármica que tem com essa família e com a irmã principalmente mais velha. E que ela é um espirito que estava vindo para trazer algumas transformações" (E17). 


\section{Os itinerários terapêuticos das gestantes adeptas às religiões afro brasileiras}

Os adeptos das religiões afro-brasileiras classificam a doença em duas categorias: a doença física, tratada pela medicina oficial; e a doença espiritual, abordada por pessoas com funções religiosas, como padres, pastores, pais e mães de santo. Sob esta ótica, recebem cuidados clínicos profissionais e, ao mesmo tempo, cuidados religiosos..$^{12}$

Com base nessa concepção, é comum que as gestantes adeptas de religiões afro-brasileiras percorram itinerários terapêuticos distintos, em paralelo ao acompanhamento pré-natal nos serviços de saúde, conforme a figura a seguir:

Figura 1. Esquema sinóptico do Itinerário Terapêutico das Mulheres adeptas de religiões afro-brasileiras no período gravídico

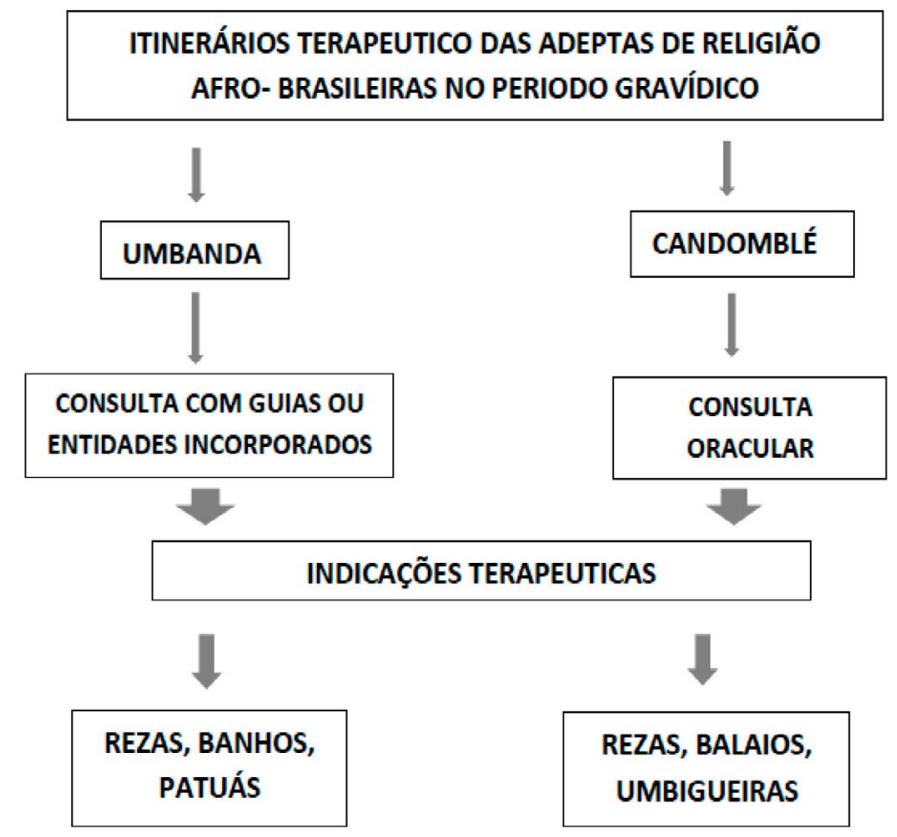

Fonte: Os autores (2021).

\section{- Consultas com oráculos}

De acordo com os ensinamentos da umbanda, o que faz a pessoa ter saúde ou adoecer é a manutenção ou o enfraquecimento do axé (palavra africana que significa força vital). $O$ axé é transmitido às pessoas nos rituais pelas várias entidades espirituais presentes na sessão espírita. Através dos médiuns (indivíduo que faz a intermediação entre as divindades e os pacientes), a entidade realiza a consulta, propiciando axé tanto para o paciente quanto ao médium. 15

No candomblé, a consulta se dá no jogo de búzios, onde os Orixás revelam as causas das doenças e dos desequilíbrios, assim como prescrevem diversos rituais para o reestabelecimento do equilíbrio físico, emocional e espiritual do indivíduo. ${ }^{16}$ Para além das consultas, algumas gestantes foram recomendadas a realizar a iniciação religiosa para alívio de seus sofrimentos.

"No momento que soube da gravidez, teve que após a consulta à Orumilá, me iniciei em Ifá e me tornei Apetebi. Meu filho também será iniciado no Ifá e batizado na religião" (E20). 
O fenômeno mediúnico está presente na religiosidade brasileira, existindo diferentes tipos de incorporações: intuitiva, auditiva, clarividência, desdobramento ou sonambúlica, psicografia, de cura, materialização, dentre outras. A mediunidade atua como um método de cura, uma terapia, uma pedagogia que transmite ensinamentos essenciais à vida comunitária e a construção da individualidade. ${ }^{17}$

"Fiz acompanhamento com o guia da casa durante a gestação. Eu era rezada por médiuns que rezavam mulheres gravidas e também bebia água rezada... Acredito que minha filha se beneficiou dessa energia também" (E04).

"Quando fui fazer a ultrassonografia eu estava com cinco meses e o doutor percebeu que tinha algo errado, pois tinha uma perna mais fina que a outra [...] fui na consulta com a preta velha e ela disse que tem coisas que não dá para mudar e daí, acho que eles já foram me preparando porque fiz uma ultrassonografia depois que a doutora viu que ele tinha mais problemas" (EO6).

Os aspectos psicológicos positivos ativados pela fé, associados aos poderes dos orixás, servem de métodos curativos utilizados pelos sacerdotes e dirigentes, compondo um mosaico amplo na Umbanda, para os leigos que procuram em momentos de maior aflição e para os "convertidos". 14

\section{- Orixás e guias espirituais envolvidos nas práticas religiosas ou nos cuidados}

Considerados na Umbanda como forças da natureza, os Orixás são energias cósmicas provindas do Criador. No candomblé, são definidos como divindades que habitam a cabeça. Cada Orixá tem sua ligação especifica com a natureza, pontos de força onde atuam, agente divinos, verdadeiros ministros da divindade suprema. ${ }^{14,18}$

"Tive preparo para Oxum para segurar, manter essa criança e foi feito um trabalho com balaios na cachoeira" (E01).

A indicação de ida à cachoeira tem por finalidade o descarrego de energias negativas e captar novas energias. O balaio é um presente dedicado a Oxum, composto pela comida preferida do orixá, frutas e outros itens: espelho, pente, sabonete e perfume. ${ }^{19}$
Espíritos hiperativos e brincalhões, os boiadeiros são como refreadores do baixo-astral, sendo rigorosos com os espíritos trevosos. Oxalá, senhor da criação e dos seres humanos, também Orixá reconhecido como importante no processo de cuidado, atuando preferencialmente na religiosidade dos seres. Sincretizado no Brasil com o Senhor do Bonfim, tem nos seus filhos 0 arquétipo de personalidade a calma. ${ }^{20}$

"Durante todo período de gestação foram feitos todos os trabalhos para Oxalá: vela de anjo de guarda acesa, arriava canjica dentro de casa. Tive colaboração de todas as religiões, era uma corrente de oração, sendo renovados e realizados até a sala de parto" (E13).

As gestantes realizaram diversas práticas religiosas durante seu pré-natal, incluindo o momento do parto. O itinerário terapêutico foi construído a partir de cada necessidade individual, incluindo cuidados biomédicos e religiosos. Durante o período gestacional, de acordo com a enfermidade e as aflições das gestantes, são prescritos diferentes trabalhos de cura, com destaque para as oferendas às entidades espirituais, orações, e banhos de limpeza do corpo e do espírito.

"Eu tive uma preparação usando alguns banhos, recolhimento, preces para anjo de guarda, vela do anjo de guarda acesa. Uma preparação para preto velho e para uma preta velha que cuida" (E12).

"Gravidez complicada, na minha segunda gestação... Repouso absoluto, não podia esticar o corpo, banho era rápido e corpo curvado. Todos os dias fazia orações às seis da manhã e seis da tarde, foi o tempo todo. Fiz trabalhos com Ibeijada e Erês, trabalhamos com os Pretos velhos, Caboclos." (E13).

"Estava de sete para oito meses quando fiz uma ultrassonografia e foi constatado que meu neném estava sentado. Fiquei muito preocupada e fui pedir ajuda na casa que frequento até hoje [...] Foi usada uma toalha branca na minha barriga, fazia as orações do jeito deles, fazia as medições na barriga. No dia seguinte tive a certeza que ela tinha ido para a posição correta. Quinze dias depois fiz uma nova ultrassonografia e ela estava na posição correta, era só aguardar o nascimento." (E14). 
Os preto-velhos são espíritos de velhos africanos que foram trazidos para o Brasil, reconhecidos como símbolos da fé e da humildade. Chamados carinhosamente de psicólogos dos aflitos, atuam nas dificuldades materiais e emocionais. Entidades mais procuradas na Umbanda, utilizam ervas em seus trabalhos de magia, voltados principalmente para doentes e crianças com mau olhado. Com rezas poderosas, recomendam patuás (saquinhos onde são depositados elementos de magia e usados no corpo para proteção), banhos de cheiro feitos com ervas especificas para cada problema, e usam cachimbos para limpeza espiritual, jogando sua fumaça sobre a pessoa que está recebendo o passe. $\frac{21}{}$

Os erês são um tipo de entidade infantil que no candomblé fazem a ponte entre o individuo iniciado e seu orixá aflorando a criança que cada um tem dentro de si. Já a ibeijada faz parte da linha das crianças na umbanda, correspondendo a espiritos que se manifestam em seus adeptos sob a forma de criança, são consideradas uma das mais fortes vibrações, sendo respeitadas por outras entidades de umbanda, tais como, preto velhos, caboclos e exus. Elas lidam com questões mais sutis, ligadas ao espirito, problemas de saúde ou ainda relacionados a crianças. ${ }^{21}$

\section{- Terapêuticas espirituais durante o trabalho de parto}

Já para o momento da parturição, predominam rituais que envolvem pontos cantados para a proteção e para o chamamento de entidades, principalmente os pretos velhos e os orixás Oxum e Xangô.

"Para a hora do parto, a religião me preparou muito, lancei mão do orixá Oxum. Na hora do parto sua presença foi muito grande... Eu era uma hipertensa com risco de ter eclampsia e na hora correu tudo muito bem" (E01).

"O ponto de Xangô ecoava na minha cabeça, me passou calma e só parou quando minha filha nasceu

Os pontos cantados atuaram como verdadeiros mantras, preces e rogativas que dinamizam forças da natureza e permitem entrar em contato com as potências espirituais que nos regem. Existe uma magia e ciência em cada ponto quando entoados com conhecimento, amor e fé. Provocam através das ondas sonoras, a atração, harmonização e dinamização das forças astrais, podendo ser um chamamento de um filho que procura ajuda ou proteção.?

Outros rituais foram citados, como o uso de fitas na cintura para irradiação divina e proteção. Tal ritual significou para a gestante maior segurança no trabaIho de parto.

"Deu tanto trabalho de um lado como do outro, tanto para obstetra como para mim, ela não acreditava muito, ela dizia, fica na sua crença, na sua fé que eu rezo da minha maneira (...), inclusive eu tinha uma fita amarrada na barriga teve que cortar na sala de parto, pois eu tinha uma fita amarrada o tempo todo na minha barriga" (E13)

\section{Intolerâncias religiosas vivenciadas pelas gestantes adeptas das religiões afro-brasileiras}

Apesar da riqueza e diversidade religiosa existente na sociedade brasileira, a intolerância religiosa ainda é uma constante no Brasil. Superar esse desafio é objeto de luta constante dos movimentos sociais e religiosos.

De acordo com a Secretaria de Direitos Humanos e Políticas para Mulheres e Idosos (SEDHMI), o estado do Rio de Janeiro registrou um aumento de $56 \%$ no número de casos de intolerância religiosa no ano de 2018 em relação à 2017. O caso Mãe Gilda, ocorrido, em 1999, resultou na primeira condenação nacional por dano moral decorrente de intolerância religiosa institucional e no estabelecimento. 22

O Conselho de Defesa e Promoção da Liberdade Religiosa, órgão ligado à Secretaria de Estado de Direitos Humanos e Políticas para Mulheres e Idosos (SEDHMI), identificou três fatores para o crescimento do número de registros: a criação de um serviço em que a sociedade confia; o entendimento que a discriminaçãoo religiosa é crime passível de denúncia; e, o agravamento dos confrontos. Confrontos religiosos têm se tornado cada vez mais constantes, com o aumento dos registros de agressões físicas, destruição de templos religiosos, demissão ou inadmissão de funcionários por conta de suas preferências religiosas. $.23,24$

As participantes deste estudo relataram vivências conflituosas nos serviços de saúde e nas relações familiares. Neste contexto, destacam que alguns profissionais de saúde demonstraram dificuldades em compreender as práticas religiosas, rituais terapêuticos 
utilizados pelas gestantes durante as consultas e procedimentos realizados nos serviços de saúde, conformando situações de intolerância religiosa institucional:

"Uma única vez que passei mal e fui para maternidade, estava com uma umbigueira, que é uma coisa que nós usamos. Eu tirei a roupa para ser examinada e me perguntaram o que é aquilo? Eu falei eu sou da religião eu expliquei que era da religião, ficaram com certo receio de me tocar..." (E01)

As práticas realizadas nos terreiros por vezes são marginalizadas e estigmatizadas, associando ao termo "macumba", palavra que algumas vezes é utilizada de forma depreciativa. A ambiguidade presente no conceito associada a preconceitos étnicos tem resultado no desconhecimento, e por vezes situações de violência obstétrica. Há uma necessidade de buscar o diálogo transcultural e transcientífico no entendimento das doenças e dos cuidados, sensibilizando os profissionais de saúde. ${ }^{25}$

No âmbito familiar, a intolerância religiosa transpareceu em relações violentas caracterizadas por agressão física ou psicológica, conforme verificado nas falas das participantes:

"Sofri do próprio pai do meu filho na quinta gestação. Por ele ser muito influenciado por pessoas evangélicas, ele me dizia que por eu ser "macumbeira" na verdade meu filho era filho do diabo" (E11).

A intolerância contra as religiões afro-brasileiras tem sito protagonizada pelos evangélicos, reproduzindo hoje o que o catolicismo fez ao longo dos trezentos e cinquenta anos de escravidão e continuou a praticar pós-abolição. O racismo religioso reproduzido pelas igrejas não livra as pessoas negras evangélicas de outras experiências de racismo, assim como não representa toda a religião protestante presente no país. ${ }^{25}$

O estudo teve como limitação a impossibilidade de algumas participantes de revelarem certos detalhes ritualísticos realizados durante o cuidado prestado nos terreiros.

\section{Conclusão}

Conhecer através do olhar das adeptas a influência da religião afro-brasileira no período gravídico possibilitou contato com práticas até então invisíveis e de difícil embasamento teórico, visto que as tradições religiosas são repassadas de forma oral com poucas publicações.

Os terreiros das religiões afro brasileiras são detentores de um saber no campo religioso, herdado de ancestrais africanos e reinventado pelas gerações afrodescendentes no Brasil com diferentes sincretismos. As práticas religiosas atuaram como alternativa e/ ou complementariedade terapêutica no processo gestacional das mulheres adeptas das religiões afro-brasileiras.

As gestantes acolhidas no terreiro foram consultadas e de acordo com suas necessidades construíram seus itinerários terapêuticos. A religião afro-brasileira possibilitou a aceitação das gestações inesperada e das perdas perinatais, com escuta sensível e apoio para seu restabelecimento. Esse cuidado foi muito valorizado pelas gestantes, sendo, para muitas, o cuidado mais efetivo do que o prestado pelo "sistema oficial de saúde".

O estudo mostrou que algumas gestantes sofreram atos de intolerância religiosa nas relações familiares e no cuidado prestado em serviços de saúde. Nesse sentido, é necessário que os profissionais de saúde possam compreender a influência das religiões afro-brasileira no período gravídico das suas adeptas, permitindo a ruptura de preconceitos, superando a desinformação sobre o cuidado aplicado nas religiões afro-brasileiras, corrigindo as distorções ideológicas por vezes existentes, reduzindo assim preconceitos e violências.

\section{Contribuições dos autores}

Mouta RJO e Freire RP participaram da redação e revisão crítica do artigo científico. Prata JA, Lopes FMVM e Teixeira ASG participaram da revisão crítica do artigo. Borges ESA participou da concepção, delineamento, coleta, análise e interpretação dos dados.

\section{Conflito de interesses}

Nenhum conflito financeiro, legal ou político envolvendo terceiros (governo, empresas e fundações privadas, etc.) foi declarado para nenhum aspecto do trabalho submetido (incluindo, mas não se limitando a subvenções e financiamentos, participação em conselho consultivo, desenho de estudo, preparação de manuscrito, análise estatística, etc.). 


\section{Referências}

1. Prisco C. As religiões de matriz Africana e a escola: guardiãs da herança cultural, memória e tradição africana. São Paulo: llè Asé e Instituto Oromilade; 2012.

2. Guimarães A. Parto sem medo. São Paulo: Mulheres que Decidem; 2016.

3. Mello ML, Oliveira SS. Saúde, religião e cultura: um diálogo partir das práticas afro-brasileiras. Saúde Soc. 2013;22(4):1024-35. https://doi.org/10.1590/S0104-12902013000400006

4. Prandi R. Mitologia dos orixás: 2001. São Paulo: Companhia das Letras; 2001.

5. Oxalá P. As Àyabás e a Maternidade [Internet]. Jornal Extra; 2012. [2012 nov 14, citado em 2021 jun 5]. Disponível em: https:// extra.globo.com/noticias/religiao-e-fe/pai-paulo-de-oxala/asayabas-a-maternidade-6739441.html

6. Ministério da Saúde (Brasil), Secretaria de Gestão Estratégica e Participativa, Departamento de Apoio à Gestão Participativa e ao Controle Social. Política Nacional de Saúde Integral da População Negra: uma política para o SUS [Internet]. Brasília: Ministério da Saúde. $3^{a}$ ed. - Brasília: Editora do Ministério da Saúde; 2017. Disponível em:

https://bvsms.saude.gov.br/bvs/publicacoes/politica nacional saude_populacao_negra_3d.pdf

7. Cabral ALLV, Martinez-Hemáez A, Andrade ELG, Cherchiglia ML. Itinerários terapêuticos: o estado da arte da produção científica no Brasil. Ciênc saúde coletiva. 2011;16(11):4433-42. https://doi. org/10.1590/S1413-81232011001200016

8. Chizzotti A. Pesquisa em ciências humanas e sociais. 8a ed. São Paulo: Cortez; 2006.

9. Ministério da Saúde (Brasil), Secretaria de Atenção à Saúde, Núcleo Técnico da Política Nacional de Humanização. Acolhimento nas práticas de produção de saúde [Internet]. 2a ed. Brasília: Ministério da Saúde.; 2010. Disponível em: https://bvsms. saude.gov.br/bvs/publicacoes/acolhimento praticas producao saude.pdf

10. Andrade JT, Mello ML, Holanda VMS. Saúde e cultura: diversidades terapêuticas e religiosas. Fortaleza: EdUECE; 2015.

11. Mello MLBC, Oliveira SS. "A vida é uma doença incuravél" Cura e cuidado na tradição de terreiros afro-brasileiros no Rio de Janeiro: Contribuições para atenção integral à saúde. Revista Temas em Educação. 2019;28(1):171-93. https://doi.org/10.22478/ ufpb.2354.7003.2019v28n1.42072

12. Araújo KA, Repetto M. A busca por saúde e a construção de itinerários em terreiros de candomblé na cidade de Boa Vista/RR. Textos e Debates. 2016;(30):9-22. http://dx.doi. org/10.18227/2217-1448ted.v2i30.4070
13. Consonni EB, Petean EBL. Perda e luto: vivências de mulheres que interromperam a gestação por malformação fetal letal. Ciênc saúde coletiva. 2013;18(9):2663-70. https://doi.org/10.1590/ $\underline{\mathrm{S} 1413-81232013000900021}$

14. Peixoto N. As flores de Obaluaê: o poder curativo dos Orixás. Porto Alegre: Besouro Box; 2018.

15. Laplantine F. Antropologia dos sistemas de representações da doença: sobre algumas pesquisas desenvolvidas na França contemporânea reexaminadas à luz de uma experiência brasileira. In: Jodelet D, organizador. As representações sociais. Rio de Janeiro: Ed UERJ; 2001. p. 241-59.

16. Mello MLBC. Práticas terapêuticas populares e religiosidade afrobrasileira em terreiros no Rio de Janeiro: um diálogo possível entre saúde e antropologia [tese] [Internet]. Rio de Janeiro: Escola Nacional de Saúde Pública Sergio Arouca; 2013. Disponível em: https://www.arca.fiocruz.br/bitstream/icict/13795/1/501.pdf

17. Campelo ML, Monteiro A. Mediniunidade e iniciação: notas sobre a iniciação de crianças na umbanda. Rev. NUFEN [Internet]. 2017;9(1):108-26. Disponível em: http://pepsic.bvsalud.org/pdf/ rnufen/v9n1/a08.pdf

18. Barbosa AJ. Para conhecer o candomblé. São Paulo: Universo dos livros; 2013.

19. Rabelo MCM. O presente de Oxum e a construção da multiplicidade no candomblé. Relig Soc. 2015;35(1):237-55. https://doi.org/10.1590/0100-85872015v35n1cap11

20. Saraceni R. As sete Linhas de Umbanda: a religião dos mistérios. São Paulo: Madras; 2003.

21. Saraceni R. Os arquétipos da Umbanda: as hierarquias espirituais dos Orixás. 2a ed. São Paulo: Madras; 2014.

22. Veleci NN. Cadê Oxum no espelho constitucional?: Os obstáculos sócio-político-culturais para o combate às violações dos direitos dos povos e comunidades tradicionais de terreiro [dissertação] [Internet]. Brasília: Universidade de Brasília; 2017. Disponível em: https://repositorio.unb.br/handle/10482/25246

23. Bento TCS, Inácio EC. “Havia um segredo que só Halima sabia": Confluências entre literature afro-brasileira e mitologia dos orixás. Anuário de Literatura. 2019;24(1):70-80. https://doi. org/10.5007/2175-7917.2019v24n1p70

24. Dias S, Gonçalves A. Migração e Saúde. Revista Migrações: Número Temático Imigração e Saúde [Internet]. 2007;(1):15-26. Disponível em: https://www.uc.pt/fluc/gigs/GeoHealthS/doc apoio/migracoes_e_saude.pdf

25. Ministério das Mulheres, da Igualdade Racial, da Juventude e dos Direitos Humanos (Brasil). Relatório sobre intolerância e violência religiosa no Brasil (2011-2015): resultados preliminares [Internet]. Brasília: Secretaria Especial de Direitos Humanos, SDH/ PR; 2016. Disponível em: https://direito.mppr.mp.br/arquivos/File/ RelatorioIntoleranciaViolenciaReligiosaBrasil.pdf 